\author{
Marek GÓRAL ${ }^{1}$ \\ Tadeusz KUBASZEK ${ }^{2}$ \\ Konrad GAJEWSKI ${ }^{3}$
}

\title{
WPŁYW WARUNKÓW KRZEMOWANIA METODĄ KONTAKTOWO-GAZOWĄ NA MIKROSTRUKTURE WARSTW NA PODŁOŻU TYTANU
}

\begin{abstract}
W artykule przedstawiono wyniki badań nad wytwarzaniem warstw krzemkowych na podłożu tytanu Grade 2 metodą kontaktowo-gazową. Stosowano dwa rodzaje proszków o różnej zawartości Si (ok. 10 i $48 \%$ mas.) oraz fluorek magnezu i aluminium jako aktywatory. Stwierdzono, że zastosowanie proszku o mniejszej zawartości krzemu skutkuje powstaniem warstw o głębokości nieprzekraczającej $5 \mu \mathrm{m}$. Zastosowanie proszku o dużej zawartości $\mathrm{Si} \mathrm{i} \mathrm{AlF}_{3}$ jako aktywatora skutkuje powstaniem wielostrefowej warstwy o głębokości ok. $15 \mu \mathrm{m}$, złożonej z faz TiSi, $\mathrm{Ti}_{5} \mathrm{Si}_{4}, \mathrm{Ti}_{5} \mathrm{Si}_{3}$ i $\mathrm{TiSi}_{2}$.
\end{abstract}

Słowa kluczowe: krzemowanie, stopy tytanu, warstwy żaroodporne, krzemki tytanu

\section{Wprowadzenie}

Stopy tytanu, cechujące się wysoką wytrzymałością względną oraz trwałością w warunkach zmęczenia i pełzania, są ważnymi materiałami stosowanymi w technice lotniczej. Podstawowe ograniczenie w zastosowaniu tych stopów stanowi mała odporność na utlenianie wysokotemperaturowe. Zwiększenie odporności korozyjnej można uzyskać przez wprowadzenie procesów wytwarzania warstw, m.in. krzemowanie. Zgodnie z układem równowagi fazowej krzem tworzy z tytanem krzemki typu $\mathrm{Ti}_{3} \mathrm{Si}_{2} \mathrm{Ti}_{5} \mathrm{Si}_{3}, \mathrm{Ti}_{5} \mathrm{Si}_{4}, \mathrm{TiSi}_{1} \mathrm{TiSi}_{2}[1,2]$. Przez ostatnie lata uwaga badaczy koncentrowała się na krzemku $\mathrm{Ti}_{5} \mathrm{Si}_{3}$, który charakteryzuje się wysoką temperaturą topnienia $\left(2130^{\circ} \mathrm{C}\right)$, gęstością $\left(4,32 \mathrm{~g} / \mathrm{cm}^{3}\right)$ mniejszą niż tytan, a przede wszystkim wysoką odpornością na utlenianie. Krzemowanie tytanu metodą kontaktowo-gazową przeprowadzili B.V. Cockeram oraz R.A. Rapp [3]. Uzyskano warstwę składającą się z pięciu faz: $\mathrm{TiSi}_{2}, \mathrm{TiSi}_{1} \mathrm{Ti}_{5} \mathrm{Si}_{4}, \mathrm{Ti}_{5} \mathrm{Si}_{3}$ oraz

\footnotetext{
1 Autor do korespondencji: Marek Góral, Politechnika Rzeszowska, al. Powstańców Warszawy 12, 35-959 Rzeszów, tel. 17 8653656, e-mail: mgoral@prz.edu.pl

2 Tadeusz Kubaszek, Politechnika Rzeszowska, e-mail: tkubaszek@ prz.edu.pl

${ }^{3}$ Konrad Gajewski, Politechnika Rzeszowska, e-mail: k.gajewskix@ gmail.com
} 
$\mathrm{Ti}_{3} \mathrm{Si}$. Wytwarzano je przy następujących warunkach procesu: temperatura 950, 1050 i $1150^{\circ} \mathrm{C}$ oraz czas 3, 6, 12 i 24 h. Jako aktywatory stosowano halogenki: $\mathrm{AlF}_{3}, \mathrm{MgF}_{2}$ i $\mathrm{CuF}_{2}$. Mieszanina proszku zawierała (\% mas.) $10 \%$ krzemu, $2 \%$ fluroku oraz $88 \%$ wypełniacza $\mathrm{Al}_{2} \mathrm{O}_{3}$. Warstwami o największej głębokości charakteryzowała się próbka wytworzona w temperaturze $1150^{\circ} \mathrm{C} w$ czasie $12 \mathrm{~h}$ przy użyciu aktywatora $\mathrm{MgF}_{2}$. Stwierdzono dużą kruchość powstałych warstw. W dalszych badaniach warstwy krzemkowe modyfikowano B oraz Ge. Jako aktywator wybrano fluorek magnezu $\mathrm{MgF}_{2}$. Uzyskano warstwę 5-strefową złożoną z różnych rodzajów krzemków tytanu i cienką warstwę $\mathrm{TiB}_{2}$ na powierzchni. Głębokość warstwy rosła wraz ze zwiększeniem aktywności boru w borku tytanu lub użyciem innego, mniej stabilnego aktywatora, jak $\mathrm{AlF}_{3} \mathrm{czy} \mathrm{CuF}_{2}$. Jednocześnie stwierdzono, że dodatek Ge spowalnia wzrost warstw $\mathrm{Ti}(\mathrm{Si}, \mathrm{Ge})$ wytwarzanych w procesie kontaktowo-gazowym z użyciem aktywatorów $\mathrm{MgF}_{2}$ i $\mathrm{AlF}_{3}$. Warstwy na podłożu stopów Ti-22Al-27Nb oraz Ti-20Al-22Nb przy modyfikacji B oraz Ge były złożone ze stref krzemków $\mathrm{TiSi}_{2} \mathrm{i}$ TiSi.

Prace nad wytworzeniem warstwy $\mathrm{Ti}_{5} \mathrm{Si}_{3}$ w dwuetapowym procesie - osadzania metodą gazową i obróbki cieplnej przeprowadzili D. Vojtech i wsp. [4]. Uzyskano na podłożu Ti warstwę o głębokości 1-2 $\mu \mathrm{m}$ i twardości $1500 \mathrm{HV}$. Stwierdzono, że warstwa ta posiada wysoką odporność na utlenianie nawet w $900^{\circ} \mathrm{C}$. J. Subrahmanyam i J. Annapurna [4] zastosowali metodę kontaktowo-gazową do wytworzenia na podłożu tytanu technicznego $(99,6 \%)$ warstwy złożonej z kryształów faz międzymetalicznych TiAl i $\mathrm{TiAl}_{3}$. Stosowano proszek złożony z fazy NiAl, aktywatora $\mathrm{NH}_{4} \mathrm{Cl}$ oraz wypełniacza $-\mathrm{Al}_{2} \mathrm{O}_{3}$. Głębokość otrzymanych warstw wynosiła od 40 do $50 \mu \mathrm{m}$. Stwierdzono, że warstwa złożona z kryształów fazy $\mathrm{TiAl}_{3}$ cechuje się lepszą odpornością na utlenianie niż warstwa złożona $\mathrm{z}$ fazy TiAl. W trakcie prób utleniania w temperaturze $1000^{\circ} \mathrm{C}$ i czasie $3 \mathrm{~h}$ stwierdzono pojawienie się warstw tlenków $\mathrm{TiO}_{2}$ oraz $\mathrm{Al}_{2} \mathrm{O}_{3}$ [5]. Dane literaturowe [3-5] wskazują, że metoda kontaktowo-gazowa pozwala na uzyskanie warstw krzemkowych na podłożu stopów tytanu. Podjęto zatem badania nad ich wytwarzaniem w różnych warunkach procesu.

\section{Materiał i metodyka badań}

W prowadzonych badaniach jako materiał podłoża przyjęto tytan techniczny gatunku Grade 2. Próbki w kształcie blaszek o wymiarach 30 x 20 mm zostały wstępnie wyszlifowane na papierze $\mathrm{SiC}$ o gradacji 320. Próbki odtłuszczano w izopropanolu. Krzemowanie metodą kontaktowo-gazową prowadzono w piecu $\mathrm{z}$ atmosferą ochronną argonu (natężenie przepływu $0,5 \mathrm{dm}^{3} / \mathrm{min}$ ) firmy Xeon. Próbki umieszczano w kontenerze wykonanym ze stali żaroodpornej, do którego zasypywano proszek złożony z krzemu, aktywatora halogenkowego i wypełniacza - tlenku $\mathrm{Al}_{2} \mathrm{O}_{3}$. Przeprowadzono 6 procesów krzemowania w różnej temperaturze i różnym czasie, $\mathrm{z}$ użyciem proszków o różnym składzie chemicznym 
(tab. 1.). Badania mikrostruktury prowadzono za pomoca skaningowego mikroskopu elektronowego HITACHII S-3400N. Dodatkowo dokonano analizy składu fazowego metodą dyfrakcji rentgenowskiej XRD.

Tabela 1. Warunki procesu krzemowania dyfuzyjnego

Table 1. Parameters of the pack siliconizing process of titanium

\begin{tabular}{|c|c|c|c|c|c|}
\hline \multirow{2}{*}{$\begin{array}{c}\text { Ozn. } \\
\text { procesu }\end{array}$} & \multicolumn{2}{|c|}{ Warunki procesu } & \multicolumn{3}{c|}{ Skład chemiczny proszku } \\
\cline { 2 - 6 } & $\begin{array}{c}\text { temperatura, } \\
{ }^{\circ} \mathrm{C}\end{array}$ & czas, $\mathrm{h}$ & $\begin{array}{c}\text { rodzaj } \\
\text { aktywatora }\end{array}$ & $\begin{array}{c}\text { zawartość ak- } \\
\text { tywatora, } \\
\% \text { mas. }\end{array}$ & $\begin{array}{c}\text { zawartość Si, } \\
\% \text { mas. }\end{array}$ \\
\hline P1 & 950 & 4 & $\mathrm{MgF}_{2}$ & 2 & 10,0 \\
\hline P2 & 950 & 2 & $\mathrm{MgF}_{2}$ & 2 & 10,0 \\
\hline P3 & 950 & 3 & $\mathrm{MgF}_{2}$ & 2 & 10,0 \\
\hline P4 & 950 & 4 & $\mathrm{AlF}_{2}$ & 3 & 48.5 \\
\hline P5 & 980 & 4 & $\mathrm{MgF}_{2}$ & 5 & 47.5 \\
\hline P6 & 980 & 8 & $\mathrm{MgF}_{2}$ & 4 & 48,0 \\
\hline
\end{tabular}

\section{Wyniki badań}

W procesie $\mathrm{P} 1$ prowadzonym w temperaturze $950^{\circ} \mathrm{C}$ w czasie $4 \mathrm{~h}$ stosowano proszek zawierający $10 \%$ mas. $\mathrm{Si}$, aktywator $\mathrm{MgF}_{2}-2 \%$ oraz wypełniacz reszta. Uzyskano warstwę o grubości od 4,32 do $6,35 \mu \mathrm{m}$. Na podstawie badań mikroskopowych stwierdzono istnienie dwóch charakterystycznych obszarów warstwy (rys. 1a, b). Ustalono, że pierwszy z nich ma budowę jednowarstwową, a zawartość Ti i Si wynosi odpowiednio 51,1 i 48,9\% at. (rys. 1a, tab. 2.). Stężenie krzemu i tytanu wskazuje na możliwość powstania krzemku TiSi. Poniżej, w mikroobszarze 2. (rys. 1a) głównym składnikiem był tytan. Analiza wyników składu chemicznego $\mathrm{w}$ drugim $\mathrm{z}$ analizowanych obszarów oraz układu równowagi Ti-Si [2] może wskazywać na powstanie krzemków typu $\mathrm{Ti}_{5} \mathrm{Si}_{4}$ lub TiSi (mikroobszary 3. i 4., rys. 1b). Drugi proces (P2) prowadzono w krótszym czasie, wynoszącym $2 \mathrm{~h}, \mathrm{z}$ użyciem proszku o takim samym składzie chemicznym. Powstała nieciągła warstwa o grubości $<3 \mu \mathrm{m}$. Jednocześnie analiza składu chemicznego w obszarze zewnętrznym warstwy (mikroobszar nr 1 na rys. 2.) wykazała małą zawartość krzemu $<1,5 \%$ at., resztę zaś stanowił tytan. W mikroobszarze 2. (rys. 2.) stwierdzono obecność jedynie tytanu.

Trzeci z procesów (P3) prowadzono w czasie $3 \mathrm{~h} \mathrm{z}$ użyciem proszku o niezmienionym - w porównaniu z procesami P1 i P2 - składzie chemicznym. Na podstawie badań mikroskopowych ustalono, że powstała warstwa ma głębokość wynoszącą od 4,32 do 4,88 $\mu \mathrm{m}$. Analiza składu chemicznego w mikroobszarach warstwy (mikroobszary nr 1 i 2 na rys. 3., tab. 3.) wykazała właściwie taką samą zawartość krzemu - 42,5\% at. oraz tytanu - 57,5\% at., co wskazuje - biorąc 
a)

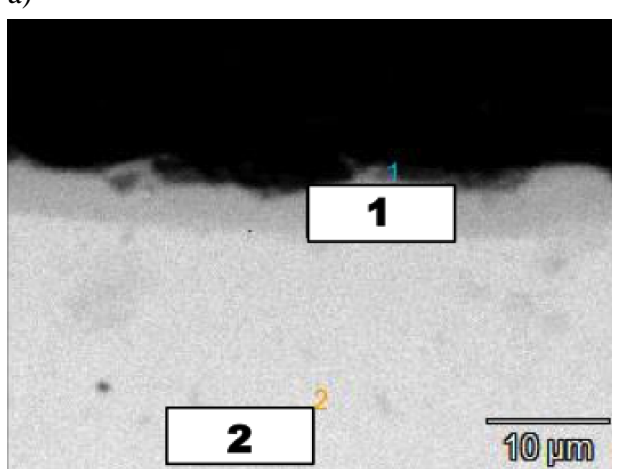

b)

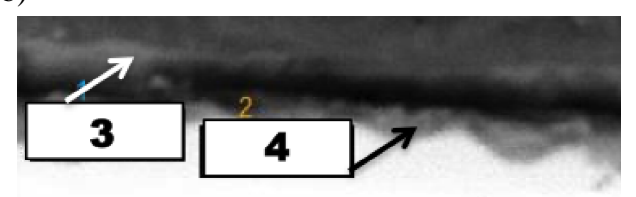

10 피요

Rys. 1. Mikrostruktura warstwy krzemkowej w obszarach o budowie: a) jedno-, b) dwuwarstwowej na podłożu tytanu wytworzonej w procesie P1 (tab. 1.)

Fig. 1. The microstruture of: a) single-, b) double silicide area of coating obtained on titanium during the $\mathrm{P} 1$ process (tab. 1.)

Tabela 2. Wyniki analizy składu chemicznego w mikroobszarach 1-4 (rys. 1a, b)

Table 2. Results of chemical composition analysis in microareas 1-4 marked on fig. 1a, b

\begin{tabular}{|c|c|c|}
\hline \multirow{2}{*}{ Mikroobszar } & \multicolumn{2}{|c|}{ Zawartość pierwiastków, \% at. } \\
\cline { 2 - 3 } & $\mathrm{Si}$ & $\mathrm{Ti}$ \\
\hline 1 & 48,9 & 51,1 \\
\hline 2 & 1,6 & 98,4 \\
\hline 3 & 44,9 & 55,1 \\
\hline 4 & 40,1 & 59,9 \\
\hline
\end{tabular}

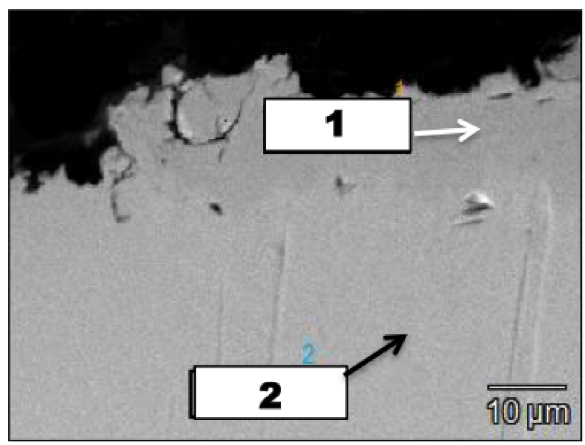

Rys. 2. Mikrostruktura warstwy krzemkowej na podłożu tytanu wytworzonej $\mathrm{w}$ procesie $\mathrm{P} 2$ (tab. 1.)

Fig. 2. The microstruture of silicide coating obtained on titanium during the $\mathrm{P} 2$ process (tab. 1.)

pod uwagę układ równowagi fazowej Ti-Si [2] - na możliwość powstania prawdopodobnie krzemków tytanu typu $\mathrm{Ti}_{5} \mathrm{Si}_{4}$. Przeprowadzenie procesu $\mathrm{P} 4$ pozwoliło na ustalenie wpływu zastosowania fluorku aluminium $\mathrm{AlF}_{3}$ jako aktywatora w procesie krzemowania tytanu. Zastosowano również proszek o dużej zawar- 
tości krzemu - 48,5\% mas. (tab. 1.). Na podstawie badań mikroskopowych ustalono, że powstała warstwa o głębokości od 13,42 do $20,50 \mu \mathrm{m}$ (rys. 4.). Na podstawie badań mikroskopowych i analizy składu chemicznego w mikroobszarach warstwy, a także układu równowagi Ti-Si [2] wyodrębniono 4 charakterystyczne strefy (rys. 4., tab. 4.):

- zewnętrzną (mikroobszar nr 1), o grubości średniej 6,6 $\mu \mathrm{m}$ i zawartości $61,8 \%$ at. $\mathrm{Si}$ oraz 38,2\% at. Ti - złożoną prawdopodobnie z krzemku TiSi 2 ,

- środkową zewnętrzną (mikroobszar nr 2) o grubości ok. $6 \mu \mathrm{m}$ i zawartości $\mathrm{Si}-46,2 \%$ at. oraz $\mathrm{Ti}-53,8 \%$ at. - złożoną prawdopodobnie z krzemków TiSi lub $\mathrm{Ti}_{5} \mathrm{Si}_{4}$,

- środkową wewnętrzną (mikroobszary nr 3,4 ) o grubości $<2 \mu \mathrm{m}$ i zawartości $\mathrm{Si}-41,6 \%$ at. oraz $\mathrm{Ti}-58,4 \%$ at., wskazującą na powstanie krzemku typu $\mathrm{Ti}_{5} \mathrm{Si}_{4}$,

- wewnętrzną (mikroobszary nr 5,6) również o grubości < $2 \mu \mathrm{m}$ o małej zawartości Si (ok. 10-16\%).

Tabela 3. Wyniki analizy składu chemicznego w mikroobszarach 1-3 (rys. 3.)

Table 3. Results of chemical composition analysis in microareas 1-3 marked in fig. 3

\begin{tabular}{|c|c|c|}
\hline \multirow{2}{*}{ Mikroobszar } & \multicolumn{2}{|c|}{ Zawartość pierwiastków, \% at. } \\
\cline { 2 - 3 } & $\mathrm{Si}$ & $\mathrm{Ti}$ \\
\hline 1 & 42,5 & 57,5 \\
\hline 2 & 42,6 & 57,4 \\
\hline 3 & 2,1 & 97,9 \\
\hline
\end{tabular}

Rys. 3. Mikrostruktura warstwy krzemkowej na podłożu tytanu wytworzonej w procesie P3 (tab. 1.)

Fig. 3. The microstructure of silicide coating obtained on titanium during the $\mathrm{P} 3$ process (tab. 1.)

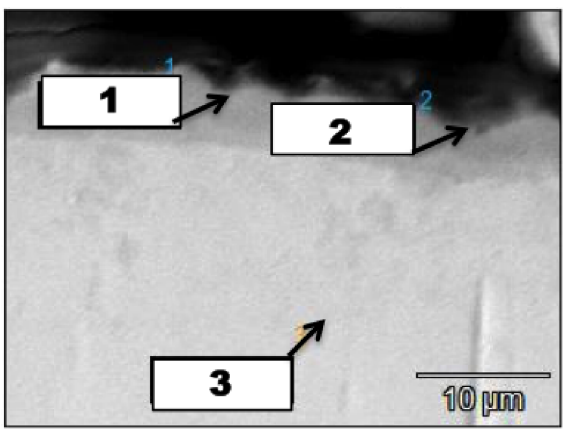

W procesie P5 zastosowano fluorek magnezu jako aktywator (2\% mas.) i proszek o dużej zawartości krzemu $-47,5 \%$ mas. Tlenek aluminium stanowił resztę. Pozostałe warunki procesu były następujące: czas $4 \mathrm{~h}$, temperatura $980^{\circ} \mathrm{C}$. Na podstawie badań mikroskopowych ustalono, że wytworzona warstwa ma głębokość od 15,9 do 17,24 $\mu \mathrm{m}$. Wyniki mikroanalizy składu chemicznego w obszarze styku warstwy z podłożem wykazały dużą zawartość tlenu i tytanu (mikro- 
obszar nr 1 na rys. 5.) co może wskazywać na pojawienie się warstewki tlenku tytanu. Jednocześnie wytworzona warstwa była złożona z dwóch stref:

- wewnętrznej (mikroobszar nr 2 na rys. 5., tab. 5.), zawierającej 43,1\% at. $\mathrm{Si}$ i 56,9\% at. Ti, złożonej prawdopodobnie z krzemku Ti ${ }_{5} \mathrm{Si}_{4}$,

- zewnętrznej (mikroobszary nr 3, 4 na rys. 5., tab. 5.), zawierającej od 47 do $57 \%$ at. Si i od 42,7 do $52,8 \%$ at. Ti.

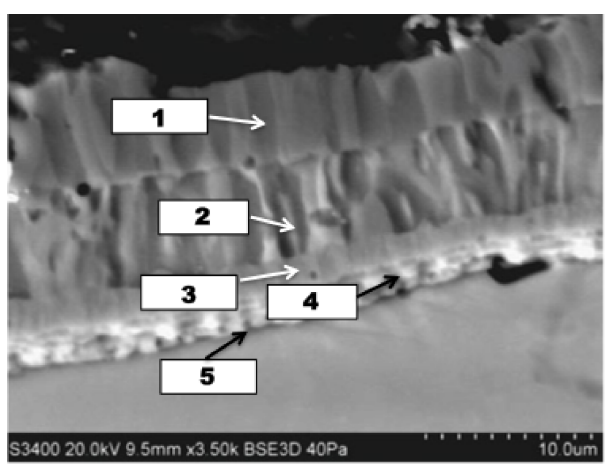

Rys. 4. Mikrostruktura warstwy krzemkowej tytanu wytworzonej w procesie P4 (tab. 1.)

Fig. 4. The microstruture of silicide coating obtained during the $\mathrm{P} 4$ process (tab. 1.)

Tabela 4. Wyniki analizy składu chemicznego w mikroobszarach 1-5 (rys. 4.)

Table 4. Results of the chemical composition analysis in microareas 1-5 marked in fig. 4

\begin{tabular}{|c|c|c|}
\hline \multirow{2}{*}{ Mikroobszar } & \multicolumn{2}{|c|}{ Zawartość pierwiastków, \% at. } \\
\cline { 2 - 3 } & $\mathrm{Si}$ & $\mathrm{Ti}$ \\
\hline 1 & 61,8 & 38,2 \\
\hline 2 & 46,2 & 53,8 \\
\hline 3 & 41,6 & 58,4 \\
\hline 4 & 10,9 & 89,1 \\
\hline 5 & 16,1 & 83,9 \\
\hline
\end{tabular}

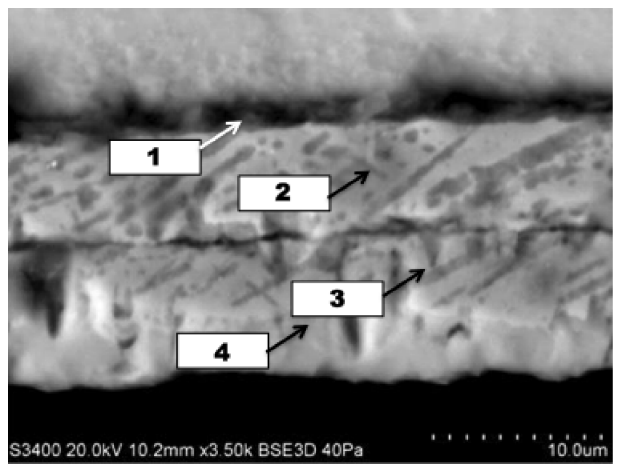

Rys. 5. Mikrostruktura warstwy krzemkowej wytworzonej w procesie P5 (tab. 5.)

Fig. 5. The microstruture of silicide coating obtained during the process marked as P5 (tab. 5.) 
Tabela 5. Wyniki analizy składu chemicznego w mikroobszarach 1-4 (rys. 5.)

Table 5. Results of the chemical composition analysis in microareas 1-4 marked in fig. 5

\begin{tabular}{|c|c|c|c|}
\hline \multirow{2}{*}{ Mikroobszar } & \multicolumn{3}{|c|}{ Zawartość pierwiastków, \% at. } \\
\cline { 2 - 4 } & $\mathrm{Si}$ & $\mathrm{Ti}$ & $\mathrm{O}^{\mathrm{s}}$ \\
\hline 1 & 17,2 & 34,8 & 47,9 \\
\hline 2 & 43,1 & 56,9 & - \\
\hline 3 & 57,3 & 42,7 & - \\
\hline 4 & 47,2 & 52,8 & - \\
\hline
\end{tabular}

Wyniki analizy składu chemicznego w strefie zewnętrznej oraz wyniki analizy składu fazowego (rys. 6.) z powierzchni wskazują na powstanie w strefie zewnętrznej krzemków tytanu typu TiSi lub $\mathrm{TiSi}_{2}$.

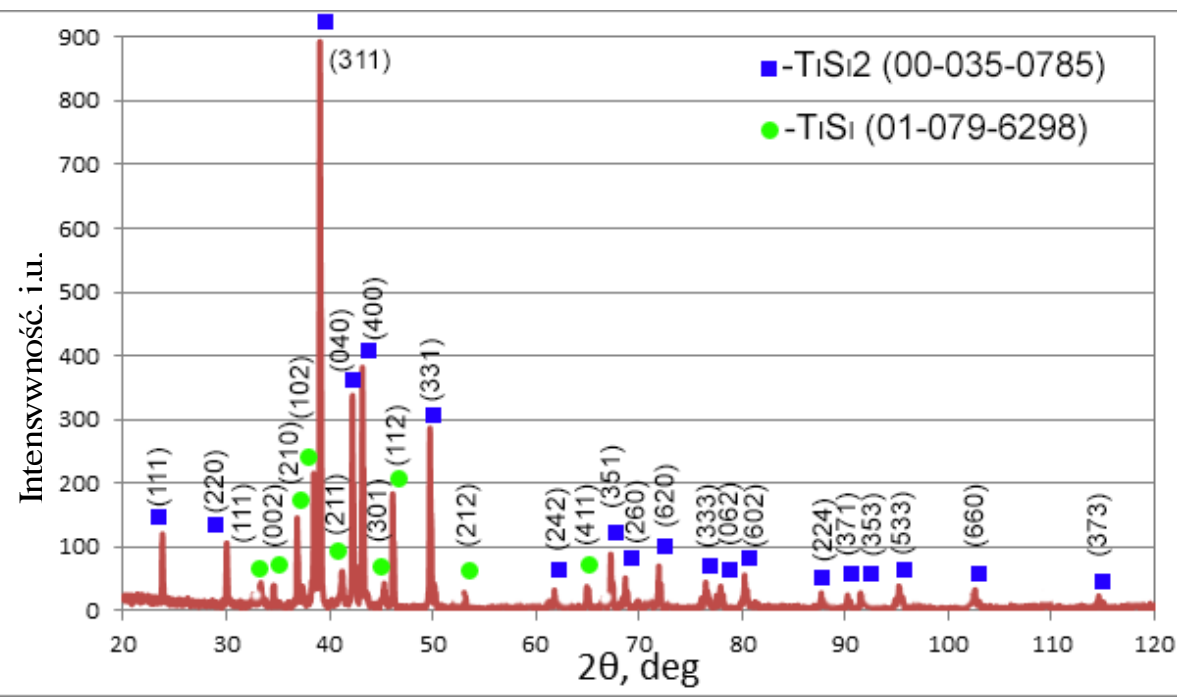

Rys. 6. Dyfraktogram z powierzchni próbki z warstwą krzemkową wytworzoną w procesie P5 (tab. 1.)

Fig. 6. XRD diffraction pattern from surface of the silicide coating obtained during the siliconizing process P5 (tab. 1.)

W ostatnim z prowadzonych procesów (P6, tab. 1.) zastosowano również proszek o dużej zawartości krzemu (48\% mas.) i fluorek magnezu jako aktywator (2\% mas.) - resztę stanowił tlenek aluminium. Zwiększono czas procesu krzemowania do $8 \mathrm{~h} \mathrm{w}$ temperaturze $980^{\circ} \mathrm{C}$. Ustalono, że głębokość wytworzonej warstwy wynosi od 8,78 do $11,1 \mu \mathrm{m}$. Badania mikroskopowe i analiza składu 
chemicznego w mikroobszarach były podstawą do wyodrębnienia dwóch charakterystycznych stref w warstwie:

- wewnętrznej (mikroobszar nr 1 na rys. 7., tab. 6.), o średniej grubości $4,9 \mu \mathrm{m}$,

- zewnętrznej (mikroobszary 2 i 3 na rys. 7., tab. 6.), o średniej grubości $7,23 \mu \mathrm{m}$, zawierającej ok. $28-32 \%$ at. Si i $64-67 \%$ at. Ti.

Analiza układu równowagi fazowej Ti-Si [2] oraz wyników mikroanalizy składu chemicznego wskazuje, że przy zmierzonej zawartości krzemu i tytanu powstaje mieszanina krzemków $\mathrm{Ti}_{3} \mathrm{Si}_{\text {oraz }} \mathrm{Ti}_{5} \mathrm{Si}_{3}$.

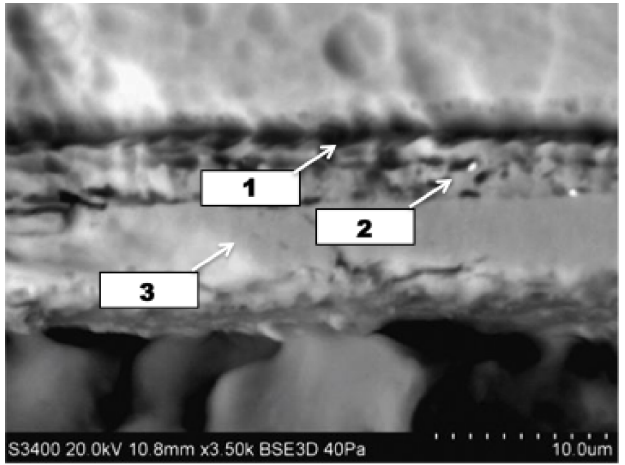

Rys. 7. Mikrostruktura warstwy krzemkowej wytworzonej w procesie P6 (tab. 1.)

Fig. 7. The microstruture of silicide coating obtained during the $\mathrm{P} 6$ process (tab. 1.)

Tabela 6. Wyniki analizy składu chemicznego w mikroobszarach 1-3 (rys. 7.)

Table 6. Results of the chemical composition analysis in microareas 1-3 marked in fig. 7

\begin{tabular}{|c|c|c|}
\hline \multirow{2}{*}{ Mikroobszar } & \multicolumn{2}{|c|}{ Zawartość pierwiastków, \% at. } \\
\cline { 2 - 3 } & $\mathrm{Si}$ & $\mathrm{Ti}$ \\
\hline 1 & 24,0 & 76,0 \\
\hline 2 & 28,2 & 63,8 \\
\hline 3 & 32,8 & 67,2 \\
\hline
\end{tabular}

\section{Podsumowanie}

Analiza wyników badań wskazuje na możliwość wytworzenia warstwy krzemkowej na podłożu stopu tytanu metodą kontaktowo-gazową. Ustalono, że parametry procesu silnie oddziałują na grubość i skład chemiczny wytworzonej warstwy. Zastosowanie proszku o małej zawartości krzemu (10\% mas., procesy P1-P3) skutkuje powstaniem cienkiej warstwy krzemków (> $5 \mu \mathrm{m})$. Wyniki analizy składu chemicznego mogą wskazywać, że głównymi składnikami fazowymi mikrostruktury mogą być krzemki typu TiSi lub $\mathrm{Ti}_{5} \mathrm{Si}_{4}$. Wykazano również, że 
czas krzemowania z użyciem tego rodzaju proszku (proces P1-P3, tab. 1.) nie wpływa istotnie na głębokość powstającej warstwy krzemkowej.

Zwiększenie zawartości Si w proszku do ok. $48 \%$ mas. skutkowało wzrostem głębokości warstwy do 10-15 $\mu \mathrm{m}$. Dodatkowo wprowadzenie fluorku $\mathrm{AlF}_{3}$ jako aktywatora spowodowało powstanie warstwy złożonej ze strefy zewnętrznej o grubości 6,6 $\mu \mathrm{m}$, zawierającej prawdopodobnie krzemek $\mathrm{TiSi}_{2}$ (mikroobszar nr 1, rys. 4.), środkowej zewnętrznej (mikroobszar nr 2, rys. 4.) również o grubości ok. $6 \mu \mathrm{m}$, złożonej z krzemku TiSi lub Ti ${ }_{5} \mathrm{Si}_{4}$, środkowej wewnętrznej (mikroobszary nr 3, 4, rys. 4.) - którą stanowią krzemki typu $\mathrm{Ti}_{5} \mathrm{Si}_{4}$ oraz wewnętrznej (mikroobszar nr 5, rys. 4.). Skład fazowy poszczególnych stref jest zbliżony do warstw uzyskanych przez Cockerhama i Rappa [3]. Zastosowanie fluorku magnezu - przy zbliżonej zawartości Si w proszku skutkuje powstaniem warstwy o mniejszej głębokości i budowie wielostrefowej, złożonej z krzemków typu TiSi, $\mathrm{Ti}_{5} \mathrm{Si}_{4}$ i $\mathrm{TiSi}_{2}$.

Badania prowadzono $w$ ramach projektu Iuventus Plus nr IP2011015471 realizowanego w latach 2012-2014.

\section{Literatura}

[1] Baszkiewicz J.: Wpływ implementacji jonów krzemu na odporność korozyjną wybranych stopów metali, OW PW, Prace Naukowe Inżynieria Materiałowa, z. 13, Warszawa 2002.

[2] Fiore M., Neto F.B., de Farias Azevedo C.R., Assesment of Ti-rich corner of Ti-Si phase diagram using two sublattices to describe the $\mathrm{Ti}_{5} \mathrm{Si}_{3}$ phase, REM, Int. Eng. J., 70 (2017) 201-207.

[3] Cockeram B.V., Rapp R.A.: The kinetics of multilayered titanium-silicide coatings grown by the pack cementation method, Metall. Mater. Trans. A, 26 (1995) 777-791.

[4] Vojtech D., Novak P., Machac P., Mort'anikova M., Jurek K.: Surface protection of titanium by $\mathrm{Ti}_{5} \mathrm{Si}_{3}$ silicide layer prepared by combination of vapor phase siliconizing and heat treatment, J. Alloys Compounds, 464 (2008) 179-184.

[5] Subrahmanyam J., Annapurna J.: High temperature cyclic oxidation of aluminide layers on titanium, Oxidation Metals, 26 (1986) 275-285.

\section{THE INFLUENCE OF PACK SILICONIZING CONDITIONS ON THE STRUCTURE OF COATINGS PRODUCED ON TITANIUM}

\section{S u m m a r y}

In the article the results of experimental pack siliconizing of titanium grade 2 alloys were presented. The powders containing low (10 wt. \%) and high (48 wt. \%) silicon content were used. The aluminium and magnesium fluorides were used as activators. The thickness of silicide coatings produced using the low-Si content powder did not exceed $5 \mu \mathrm{m}$. The use of high Si content pack 
enabled to form thick $(15 \mu \mathrm{m})$ multilayer coating formed from $\mathrm{TiSi}, \mathrm{Ti}_{5} \mathrm{Si}_{4}, \mathrm{Ti}_{5} \mathrm{Si}_{3}$ and $\mathrm{TiSi}_{2}$ silicides.

Keywords: silicide coatings, pack siliconizing, titanium alloys, heat resistant coatings, titanium silicides

DOI: $10.7862 / \mathrm{rm} .2019 .02$

Otrzymano/received: $24.02 .2019 r$.

Zaakceptowano/accepted: 27.05.2019 r. 